\title{
Severe constipation as the first clinical manifestation in multiple endocrine neoplasia type 2B: a case report and literature review
}

\author{
Lidan Zhang ${ }^{1}$, Yan Guo', Lei Ye², Wenli Lu', Zhiya Dong ${ }^{1}$, Wei Wang ${ }^{1}$ and Yuan Xiao ${ }^{1 *}$ (D)
}

\begin{abstract}
Background: The occurrence of multiple endocrine neoplasia type 2B (MEN2B) in Asians is very rare. In particular, patients with intractable constipation as the main clinical manifestation are even rarer. Atypical clinical manifestations are likely to lead to a diagnostic delay. In this report, we described a case of a delayed diagnosis of MEN2B, and the first clinical manifestation was intractable constipation.

Case presentation: A female teenager had suffered from intractable constipation since infancy. Because the colonoscopy and biopsy results from local hospitals did not confirm the presence of congenital megacolon, the girl had been followed up at a local clinic for a long time. The diagnosis was not confirmed until thyroid masses were found in the Pediatric Department of Shanghai Ruijin Hospital when she was 12 years old. According to our detailed evaluation, she suffered from Hirschsprung disease (HD), growth retardation, medullary thyroid carcinoma (MTC) and mucosal neuroma due to a mutation in the RET gene. Thus, the diagnosis of MEN2B was confirmed. Afterward, the girl underwent several surgeries and was still being followed up before the article was published.

Conclusion: MEN2B has atypical clinical symptoms in the early stage. Refractory constipation may be the only clinical manifestation that lasts for several years. Therefore, we recommend that early screening and gene sequencing should be performed for patients with severe constipation due to HD to determine the cause of the disease and to improve the survival outcome.
\end{abstract}

Keywords: Multiple endocrine neoplasia 2B, Medullary thyroid carcinoma, Multiple mucosal neuroma, Hirschsprung disease, Proto-oncogene

\section{Background}

Multiple endocrine neoplasia (MEN) is a general term for two or more endocrine glands with tumor lesions. According to its clinical manifestations and types of mutation, this condition can be divided into MEN1 (Online Mendelian Inheritance in Man (OMIM) number:

\footnotetext{
* Correspondence: xy11438@rih.com.cn

'Department of Pediatrics, Ruijin Hospital, Shanghai Jiao Tong University School of Medicine, Shanghai 200025, China

Full list of author information is available at the end of the article
}

131100), MEN2 and familial medullary thyroid carcinoma (FMTC) (OMIM number: 155240). Furthermore, MEN2 also has two subtypes: MEN2A (OMIM number: 171400) and MEN2B (OMIM number: 162300). MEN2B is a rare autosomal dominant genetic disease caused by a mutation of the RET proto-oncogene. The main clinical manifestations are medullary thyroid carcinoma (MTC), multiple mucosal neuroma, pheochromocytoma (PHEO), and Marfan-like habitus [1]. The overall incidence of MEN2B is approximately 1:35,000 1:40,000

C C The Author(s). 2020 Open Access This article is licensed under a Creative Commons Attribution 4.0 International License, which permits use, sharing, adaptation, distribution and reproduction in any medium or format, as long as you give appropriate credit to the original author(s) and the source, provide a link to the Creative Commons licence, and indicate if changes were made. The images or other third party material in this article are included in the article's Creative Commons licence, unless indicated otherwise in a credit line to the material. If material is not included in the article's Creative Commons licence and your intended use is not permitted by statutory regulation or exceeds the permitted use, you will need to obtain permission directly from the copyright holder. To view a copy of this licence, visit http://creativecommons.org/licenses/by/4.0/ The Creative Commons Public Domain Dedication waiver (http://creativecommons.org/publicdomain/zero/1.0/) applies to the data made available in this article, unless otherwise stated in a credit line to the data. 
[2], and it only accounts for $5-10 \%$ of all cases of MEN2 [3]; MEN2B was officially named by Chong [4] in 1975. To date, only 20 cases of MEN2B have been reported in mainland China, and few cases of children have been documented.

Patients with MEN2B often have gastrointestinal (GI) symptoms such as abdominal pain, constipation or diarrhea due to Hirschsprung disease (HD), which usually occurs during childhood and early adulthood [5, 6]. Approximately $50 \%$ of the patients in China had gastrointestinal tract involvement, and such conditions were noted in $61-90 \%$ of patients with different ethnicities [7, 8]. However, the non-MTC clinical manifestations were often overlooked, leading to misdiagnosis. The average age of diagnosis of MEN2B is 14.2 years old [8].

Here, we report a case of a Chinese girl with MEN2B who had severe constipation since infancy due to a pathogenic mutation in RET.

\section{Case presentation Clinical data}

A 12-year-old girl born in the Zhejiang Province of China was admitted to the Department of Pediatrics, Ruijin Hospital, Shanghai Jiao Tong University School of Medicine in February 2016 with chief complaints of constipation for 12 years and neck lumps for 2 years. She was the first-born child to her parents and was born at 38 weeks and 4 days of gestation after an unremarkable pregnancy. No obvious abnormalities were found during her neonatal period. She had experienced constipation since infancy. The patient had no family history of MTC or HD. Nevertheless, she had a younger half-brother with pancreatic dysplasia with whom she shared a father. She underwent colonoscopy in a local tertiary hospital due to her intractable constipation when she was 2 years old. However, the diagnosis of congenital megacolon could not be confirmed according to the results of the intestinal biopsy. Afterward, she was followed up at a clinic. Two masses were found in her neck 2 years ago and have gradually increased in size since being identified.

On the examination, her weight was $26.8 \mathrm{~kg}(-2.08$ $\mathrm{SD})$, her height was $136 \mathrm{~cm}(-2.56 \mathrm{SD})$ and she had a BMI of $14.49 \mathrm{~kg} / \mathrm{m}^{2}(-1.57 \mathrm{SD})$. She had not exhibit Marfan-like habitus. Her external genitalia and breasts were Tanner stage I, and she had no pubic hair. Therefore, she had not yet undergone puberty. Her blood pressure was $100 / 64 \mathrm{mmHg}$. The physical examination also revealed multiple painless, firm nodules on her gingival tissue, tongue and buccal mucosa, and these were considered mucosal neuromas (Fig. $1 \mathrm{a}, \mathrm{b}$ ). Her thyroid was enlarged, and multiple hard nodules could be palpable on the surface of the thyroid (Fig. $1 \mathrm{c}$ ). There was no palpable mass in her abdomen.
Her serum levels of free triiodothyronine (FT3), free tetraiodothyronine (FT4) and thyroid-stimulating hormone (TSH) were normal, but her calcitonin level was very high $(1187 \mathrm{pg} / \mathrm{ml})$, and her parathyroid hormone (PTH) level was slightly elevated (Table 1). Moreover, her serum carcinoembryonic antigen (CEA) level was much higher than normal $(655.4 \mathrm{ng} / \mathrm{ml})$. The level of insulin-like growth factor 1 level $(61 \mathrm{ng} / \mathrm{ml})$ was lower than the normal reference according to her age. Her other hormone (serum insulin, growth hormone, prolactin, cortisol, adrenaline, norepinephrine) level and electrolyte levels were normal (Table 1).

Two masses were found in each lobe of her thyroid along with multiple metastatic lymph nodes by ultrasound (Fig. $1 \mathrm{~d}$ ). The size of the right mass was $37 \mathrm{~mm} \times$ $20 \mathrm{~mm}$ and that of the left mass was $43 \mathrm{~mm} \times 20 \mathrm{~mm}$ (Fig. 1 e). Both masses were classified as Thyroid Imaging Reporting and Data System (TI-RADS) 5. The abdominal X-ray and CT scan revealed transverse colonic dilatation and colonic wall thickening (Fig. $1 \mathrm{f}, \mathrm{g}$, $\mathrm{h}$ ), which suggested a diagnosis of megacolon. There were no obvious abnormalities in her head MRI or adrenal CT scan.

She underwent an extended radical thyroidectomy and cervical lymph node dissection for thyroid cancer. As expected, the postoperative pathological diagnosis changed to bilateral MTC (T3N1bM0 (stage IV A)), with 24/38 metastases observed in the lymph nodes (Fig. 2a, b, c, d).

\section{Genetic test}

A pathogenic mutation in the RET gene (c.2753 T > C, p. $\mathrm{M} 918 \mathrm{~T}$ ) was found in the proband but not in her father or in her younger half-brother (Fig. 3). Since her mother's DNA was not obtained, it was impossible to determine whether the mutation was de novo. However, this is a hot spot variation in $R E T$, and it has been proven to be a causative mutation of MEN2B. According to the American College of Medical Genetics and Genomics (ACMG) guidelines, this mutation was defined as a pathogenic variation [9]. Finally, a diagnosis of MEN2B was confirmed by phenotyping and genotyping.

\section{Follow-up}

After the operation, the patient was given L-thyroxine $50 \mu \mathrm{g} / \mathrm{d}$ as substitution therapy. The dosage was adjusted according to her thyroid function, which was reviewed regularly in our pediatric endocrinology clinic.

Her calcitonin level decreased gradually from $1187 \mathrm{pg} /$ $\mathrm{ml}$ to $850.8 \mathrm{pg} / \mathrm{ml}$. The calcitonin level increased again and reached $1072.1 \mathrm{pg} / \mathrm{ml} 5$ months after the first operation. Then, she was arranged to undergo another CT scan. Afterward, cervical lymph node and mediastinal metastases of the MTC were confirmed. In September 2016, she underwent mediastinal tumor resection and 

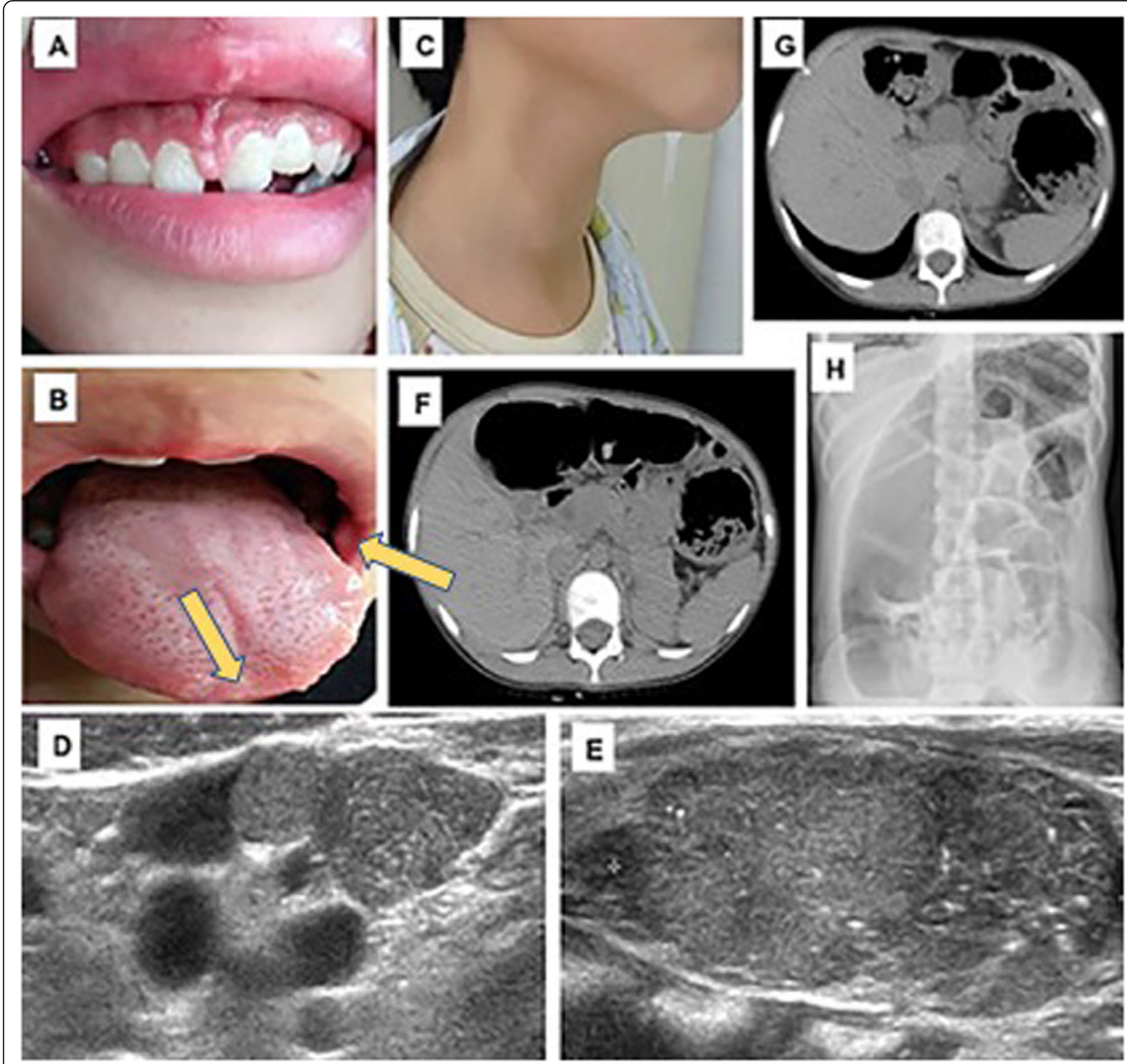

Fig. 1 Clinical Characteristics of the Patient (a) Thickened lips. (b) Neuromas affecting the gingival tissue, tongue and oral mucosa (as yellow arrows indiated). (c) Thyroid nodule. (d) Multiple metastatic lymph nodes .(e) Thyroid enlargement (with multiple calcifications). (f)(g) Colon dilatation.(h) Colon wall thickening

extended radical surgery for thyroid cancer. Since this surgery, the serum levels of calcitonin and CEA have fluctuated within $442.5 \mathrm{pg} / \mathrm{ml} \sim 2000 \mathrm{pg} / \mathrm{ml}$ and $9.95 \mathrm{ng} /$ $\mathrm{ml} \sim 98.32 \mathrm{ng} / \mathrm{ml}$, respectively.

In October 2017, the child underwent colectomy in another hospital because of severe constipation induced by megacolon. She was diagnosed with HD since the pathology of colon indicated ganglioneuromatosis in the whole colon.

Since then, she has achieved catch-up growth and has been followed in our pediatric clinic for monitoring of her growth and development, IGF-1 level, blood pressure, thyroid function, adrenal function, and levels of CEA and calcitonin (Fig. 4a, b). She began puberty after the MTC was removed and menstruated 1 year ago. During the most recent follow-up, she was $156.8 \mathrm{~cm}$ $(-0.62 \mathrm{SD})$ tall.

\section{Discussion and conclusions}

The clinical symptoms of MEN2B include mucosal neuroma, Marfan-like habitus, thyroid carcinoma (especially MTC), PHEO, gastrointestinal symptoms, and specialized facial features. MEN2B combined with GI symptoms mainly includes abdominal pain, constipation or 
Table 1 Main results of laboratory investigations on the patient before the first surgery

\begin{tabular}{|c|c|c|c|}
\hline Variable & Unit & Reference Range & On admission \\
\hline $\mathrm{TSH}$ & $\mathrm{ulU} / \mathrm{ml}$ & $0.35-4.94$ & 3.09 \\
\hline FT3 & $\mathrm{pmol} / \mathrm{l}$ & $2.63-5.70$ & 5.24 \\
\hline FT4 & $\mathrm{pmol} / \mathrm{l}$ & $9.01-19.04$ & 13.85 \\
\hline T3 & $\mathrm{nmol} / \mathrm{l}$ & $0.89-2.40$ & 1.80 \\
\hline T4 & $\mathrm{nmol} / \mathrm{l}$ & $62.6-150.8$ & 94.11 \\
\hline Calcitonin & $\mathrm{pg} / \mathrm{ml}$ & $<10$ & $>1187$ \\
\hline PTH & $\mathrm{pg} / \mathrm{ml}$ & $15.0-68.3$ & 75.5 \\
\hline CEA & $\mathrm{ng} / \mathrm{ml}$ & $<5.0$ & 655.4 \\
\hline AFP & $\mathrm{ng} / \mathrm{ml}$ & $0-8.78$ & 2.92 \\
\hline $\mathrm{Ca}$ & $\mathrm{mol} / \mathrm{l}$ & $2.0-2.75$ & 2.29 \\
\hline P & $\mathrm{mol} / \mathrm{l}$ & $0.8-1.6$ & 1.62 \\
\hline$E$ & $\mathrm{pg} / \mathrm{ml}$ & $14-90$ & 57.4 \\
\hline NE & $\mathrm{pg} / \mathrm{ml}$ & 19-121 & 94.4 \\
\hline IGF-1 & $\mathrm{ng} / \mathrm{ml}$ & $385-665$ & 61 \\
\hline
\end{tabular}

Remark: TSH Thyroid stimulating hormone, FT3 Free triiodothyronine, FT4 Free tetraiodothyronine, $T 3$ Triiodothyronine, T4 Tetraiodothyronine, PTH Parathyroid hormone, CEA Carcinoembryonic antigen, AFP Alpha-fetoprotein, $P$ Phosphorus, E Epinephrine, NE Norepinephrine, IGF-1 Insulin-like growth factors -1

diarrhea, and often includes megacolon disease. Megacolon symptoms usually occur in childhood and early adulthood [10]. Approximately 50\% of Chinese patients have gastrointestinal symptoms, while this prevalence in other races is approximately $61-90 \%[7,8]$. However, the non-MTC clinical manifestations are often overlooked, leading to a delayed diagnosis. The average age

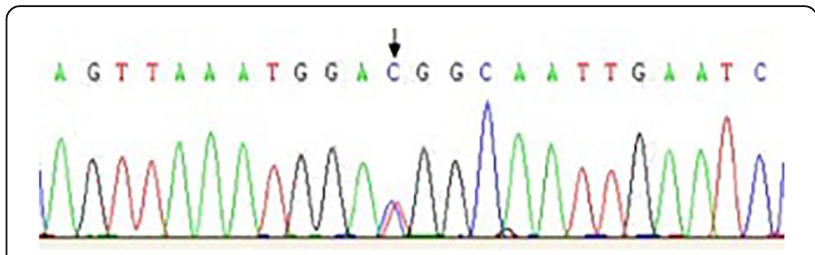

Fig. 3 RET gene mutation site sequencing map (c. T2753C, p. M918T) of the patient

of diagnosis of MEN2B is 14.2 years [8]. In this case, the patient had got intractable constipation since early infancy. She was not diagnosed until a neck mass was found. However, lymph node metastasis and thymus metastasis occurred when MTC was diagnosed, and the best surgical opportunity had been missed. It has been suggested that RET gene sequencing should be performed to rule out MEN2B when HD is considered [11]. The curative rate of early thyroidectomy for MTC without metastasis can reach as high as $100 \%$. Since the prevalence of MTC is $100 \%$ in patients with the p.M918T mutation of the RET gene, the current guidelines of the American Thyroid Association (ATA) recommend that if children have this mutation, thyroidectomy be performed before the patients reach 1 year in age to prevent MTC in the future [2]. Thus, the early diagnosis of MEN2B and RET gene sequencing are important to improving the prognosis of suspected children without a familial history of MTC. It is useful to perform $R E T$ proto-oncogene detection in infants with $\mathrm{HD}$, and
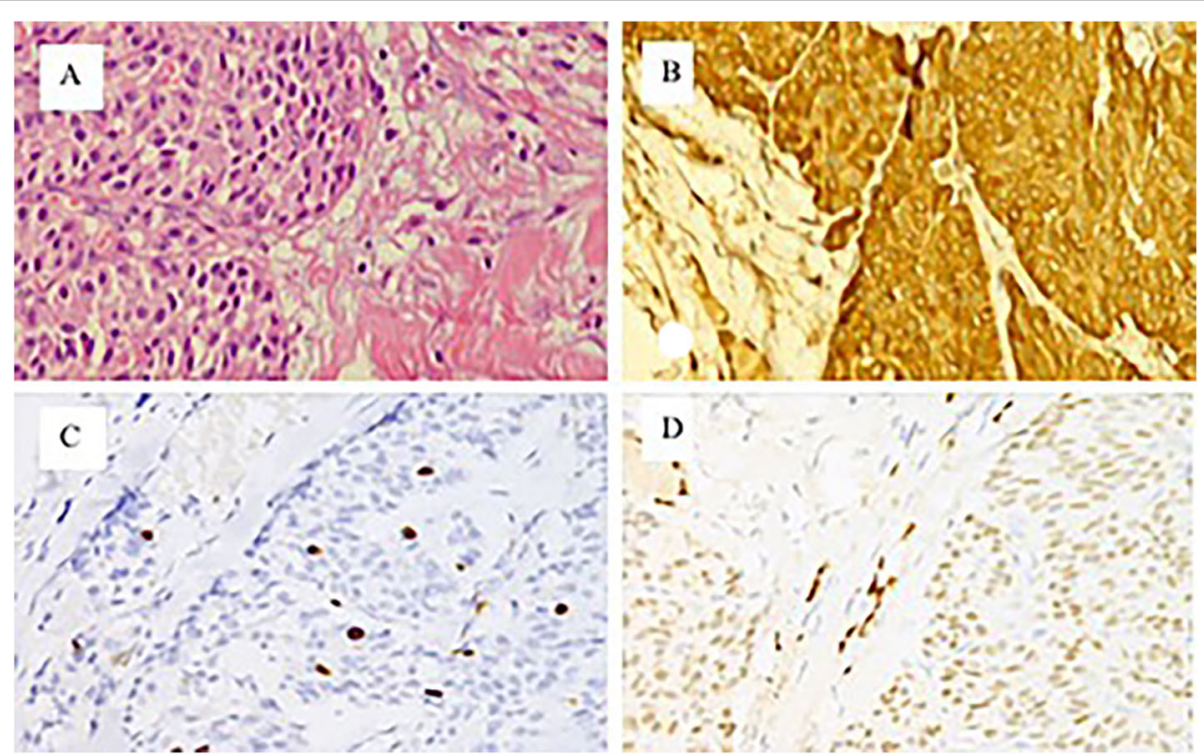

Fig. 2 Pathological image of the thyroid tumor (a) Pathological image of the thyroid tumor (HE staining, $40 \times 10$ ), showing the arrangement of spindle-shaped medullary carcinoma cells and amyloid deposition; $(\mathbf{b})(\mathbf{c})(\mathbf{d})$ are immunohistochemical photomicrographs $(\mathrm{DAB}$ staining, $40 \times 10)$ that suggest calcitonin (+), Ki67 (+), and TTF-1 (+) 

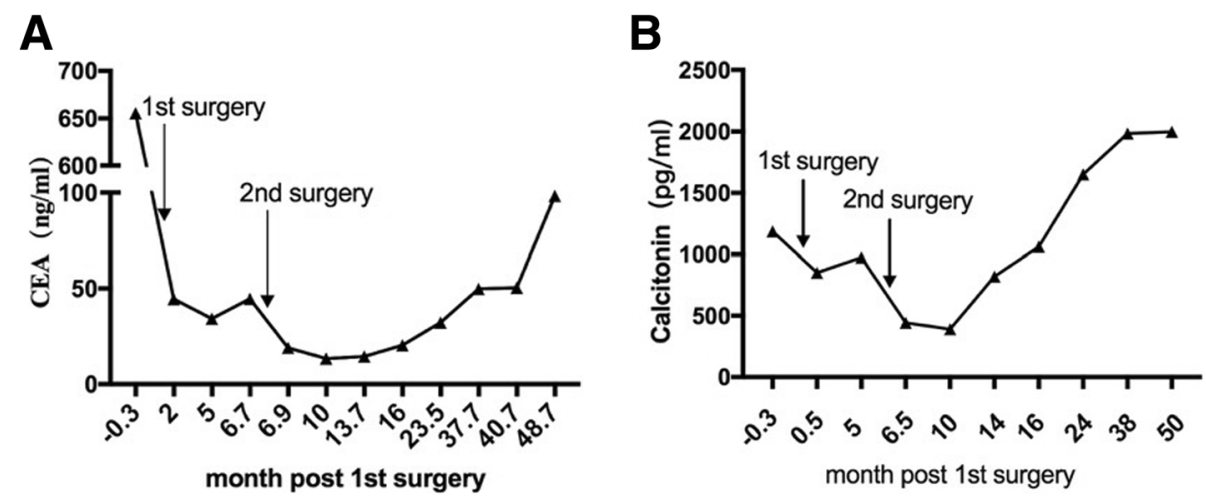

Fig. 4 a Follow-up of the CEA index $\mathbf{b}$ Follow-up of the calcitonin index

this analysis may find new sporadic patients with MEN2 [12]. Additionally, mucosal neuromas and intestinal ganglioneuromas are characteristic signs and pathological findings of MEN2B, respectively, and can contribute to screening for MEN2B. In our case, the girl developed mucosal neuromas on her tongue, lip and buccal mucosa. If these characteristics had been recognized by local doctors, she might have undergone thyroidectomy much earlier than she did.

In the PubMed database, 927 articles were related to MEN2B, of which 261 cases were of patients aged 0-18 years old. In these articles, the clinical manifestations of MEN2B were as follows: mucosal neuroma and Marfanlike habitus were observed in $99 \%$ of all cases, MTC was observed in 95\%, and PHEO was observed in 50\% [2, 13, 14]. However, more than $95 \%$ of the patients with MEN2B carried the p. M918T mutation of RET. After we searched Chinese articles in the Wanfang and CNKI databases, we found 20 MEN2B cases, of which $35 \%$ of the patients (7 patients) were diagnosed in childhood. Among these patients, 95, 95, 80, 50, and 50\% had MTC, mucosal neuroma, Marfan-like habitus, PHEO, and GI symptoms, respectively. After thyroidectomy, most patients had high serum calcitonin levels. It is still unknown whether these patients are still alive. Among these patients, 12 had gene sequencing, and all of them had p.M918T mutations in RET.

At present, genetic testing is still the gold standard for diagnosing MEN2B. Because of the low incidence and poor prognosis of MEN2B, RET gene screening should be performed early for suspected cases.

MTC is a poorly differentiated cancer with a high degree of malignancy. Since MTC is not sensitive to radiotherapy and chemotherapy, surgery is the only cure for MTC. For MTC in the early stage without metastasis, the curative rate of thyroidectomy may reach $100 \%$. Once lymph node metastasis occurs, however, the risk for metastasis after lymph node dissection is also high
[15]. Targeted drugs such as vandetanib and cabozantinib have been used for metastatic MTC [16-18]. It was confirmed that these targeted drugs significantly alleviate clinical symptoms [17]. The use of these drugs is also warned against because of the potential side effects of heart disease. MTC may develop resistance to these drugs within a few years. Furthermore, the safety and efficacy of such drugs in children are unclear. In recent years, some new RET inhibitors, such as alectinib (Roche), Blu-667 and Loxo-292, have been tested in Phase I trials [19]. When the calcitonin doubling time was between 0.5 and 2 years, the 5 -year and 10 -year survival rates of MTC were 92 and 37\%, respectively. Furthermore, when the calcitonin doubling time was $<6$ months, the 5-year and 10-year survival rates decreased to 25 and $8 \%$, respectively [20,21]. In this case, her calcitonin doubling time was more than 6 months. In addition, she started puberty, had a growth spurt after her second operation, and menstruated when she was 14 years old. These findings indicated that the condition of the female adolescent deteriorated relatively slowly. Her calcitonin and CEA levels were very high, which indicated there was a metastasis of the MTC despite no positive findings from the CT scan. Because vandetanib is not approved in mainland China, we could only monitor her more frequently and thoroughly during the follow-up period.

In conclusion, p.M918T mutation of the RET gene accounted for more than $95 \%$ of all cases of MEN2B. Intractable constipation due to HD may be an early warning sign of MEN2B. Clinicians should follow these patients for a long time and pay attention to the presence of neck masses, mucosal neuroma or elevated blood pressure. $R E T$ gene sequencing can distinguish patients suffering from MEN2B from those suffering from other conditions in a timely manner to provide early treatment, which is the most important factor for changing the prognosis of MEN2B. 


\section{Abbreviations}

MEN 2B: Multiple endocrine neoplasia type 2B; MTC: Medullary thyroid carcinoma; MEN: Multiple endocrine neoplasia; FMTC: Familial medullary thyroid carcinoma; Gl: Gastrointestinal; PHEO: Pheochromocytoma; ACMG: American College of Medical Genetics and Genomics guidelines; CEA: Carcinoembryonic antigen; ATA: American Thyroid Association; $\mathrm{CT}$ : Computed tomography

\section{Acknowledgements}

All authors thank Dr. Xi Chen of Thyroid Surgery and Dr. Xiaochun Fei of Pathology Department in the Ruijin Hospital for the assistance in surgery and pathological imaging.

\section{Conflict of interest}

No conflict of interest exists in the submission of this manuscript, and the manuscript is approved by all authors for publication. Each author listed on the manuscript has seen and approved the submission of this version of the manuscript and takes full responsibility for the manuscript.

\section{Authors' contributions}

LZ wrote this article. YG, LY,WL, ZD, WW collected all the clinical information of these patients. $Y X$ is the corresponding author who edited and reviewed this case report and approved the version to be published. All authors have read and approved the final manuscript.

\section{Funding}

This study was supported by the Shanghai Municipal Commission of Health and Family Planning Project (201640368). The owner of this fund, YuanXiao, is the corresponding author of this article. He edited and reviewed this case report and approved the version to be published.

\section{Availability of data and materials}

The data and materials are available from the corresponding author (Yuan Xiao) on reasonable request.

\section{Ethics approval and consent to participate}

Regarding genetic testing, doctors and patients and their guardians fully communicated and signed the informed consent form before the formal implementation of genetic testing. Ethic committee approval for the study was granted by IRB at Ruijin Hospital, Shanghai Jiao Tong University, School of Medicine.

\section{Consent for publication}

Verbal and written consent for this case report was obtained from the girl's father and herself because her parents had divorced and we were unable to contact her mother.

\section{Competing interests}

No conflict of interest to report.

\section{Author details}

Department of Pediatrics, Ruijin Hospital, Shanghai Jiao Tong University School of Medicine, Shanghai 200025, China. ${ }^{2}$ Department of Endocrine and Metabolism, Ruijin Hospital, Shanghai Jiao Tong University School of Medicine, Shanghai 200025, China.

Received: 30 April 2020 Accepted: 22 June 2020

Published online: 29 June 2020

\section{References}

1. Maclntosh RB, Shivapuja PK, Krzemien MB, Lee M. Multiple endocrine neoplasia type 2B: maxillofacial significance in 5 cases. J Oral Maxillofac Surg. 2014;72(12):2498.e2491-17.

2. Wells SA Jr, Asa SL, Dralle H, Elisei R, Evans DB, Gagel RF, Lee N, Machens A, Moley JF, Pacini F, et al. Revised American Thyroid Association guidelines for the management of medullary thyroid carcinoma. Thyroid. 2015;25(6): 567-610.

3. Vasen HF, van der Feltz M, Raue F, Kruseman AN, Koppeschaar HP, Pieters G, Seif FJ, Blum WF, Lips CJ. The natural course of multiple endocrine neoplasia type IIb. A study of 18 cases. Arch Intern Med. 1992;152(6):1250-2.
4. Chong GC, Beahrs OH, Sizemore GW, Woolner LH. Medullary carcinoma of the thyroid gland. Cancer. 1975;35(3):695-704

5. Camacho CP, Hoff AO, Lindsey SC, Signorini PS, Valente FO, Oliveira MN Kunii IS, Biscolla RP, Cerutti JM, Maciel RM. Early diagnosis of multiple endocrine neoplasia type 2B: a challenge for physicians. Arq Bras Endocrinol Metabol. 2008:52(8):1393-8.

6. Feichter S, Meier-Ruge WA, Bruder E. The histopathology of gastrointestinal motility disorders in children. Semin Pediatr Surg. 2009;18(4):206-11.

7. Leboulleux S, Travagli JP, Caillou B, Laplanche A, Bidart JM, Schlumberger M, Baudin E. Medullary thyroid carcinoma as part of a multiple endocrine neoplasia type 2B syndrome: influence of the stage on the clinical course. Cancer. 2002;94(1):44-50.

8. Brauckhoff M, Gimm O, Weiss CL, Ukkat J, Sekulla C, Brauckhoff K, Thanh PN, Dralle H. Multiple endocrine neoplasia 2B syndrome due to codon 918 mutation: clinical manifestation and course in early and late onset disease. World J Surg. 2004;28(12):1305-11.

9. Amendola LM, Jarvik GP, Leo MC, McLaughlin HM, Akkari Y, Amaral MD Berg JS, Biswas S, Bowling KM, Conlin LK, et al. Performance of ACMGAMP variant-interpretation guidelines among nine Laboratories in the Clinical Sequencing Exploratory Research Consortium. Am J Hum Genet. 2016;99(1):247.

10. King SK, Southwell BR, Hutson JM. An association of multiple endocrine neoplasia 2B, a RET mutation; constipation; and low substance P-nerve fiber density in colonic circular muscle. J Pediatr Surg. 2006;41(2):437-42.

11. Gfroerer S, Theilen TM, Fiegel H, Harter PN, Mittelbronn M, Rolle U. Identification of intestinal ganglioneuromatosis leads to early diagnosis of MEN2B: role of rectal biopsy. J Pediatr Surg. 2017;52(7):1161-5.

12. Fialkowski EA, DeBenedetti MK, Moley JF, Bachrach B. RET proto-oncogene testing in infants presenting with Hirschsprung disease identifies 2 new multiple endocrine neoplasia 2A kindreds. J Pediatr Surg. 2008;43(1):188-90.

13. Frank-Raue K, Rondot S, Raue F. Molecular genetics and phenomics of RET mutations: impact on prognosis of MTC. Mol Cell Endocrinol. 2010; 322(1-2):2-7.

14. Khatami F, Tavangar SM. Multiple endocrine Neoplasia syndromes from genetic and epigenetic perspectives. Biomark Insights. 2018;13: 1177271918785129.

15. Wells SA Jr, Pacini F, Robinson BG, Santoro M. Multiple endocrine neoplasia type 2 and familial medullary thyroid carcinoma: an update. J Clin Endocrinol Metab. 2013:98(8):3149-64.

16. Thornton K, Kim G, Maher VE, Chattopadhyay S, Tang S, Moon YJ, Song $\mathrm{P}$, Marathe A, Balakrishnan S, Zhu H, et al. Vandetanib for the treatment of symptomatic or progressive medullary thyroid Cancer in patients with Unresectable locally advanced or metastatic disease: U.S. Food and Drug Administration drug approval summary. Clin Cancer Res. 2012; 18(14):3722-30

17. Wells SA Jr, Robinson BG, Gagel RF, Dralle H, Fagin JA, Santoro M, Baudin E, Elisei $R$, Jarzab B, Vasselli JR, et al. Vandetanib in patients with locally advanced or metastatic medullary thyroid cancer: a randomized, doubleblind phase III trial. J Clin Oncol. 2012;30(2):134-41.

18. Elisei $R$, Schlumberger MJ, Muller SP, Schoffski P, Brose MS, Shah MH, Licitra $L$, Jarzab B, Medvedev V, Kreissl MC, et al. Cabozantinib in progressive medullary thyroid cancer. J Clin Oncol. 2013;31(29):3639-46.

19. Nelkin B. Recent advances in the biology and therapy of medullary thyroid carcinoma. F1000Research. 2017;6:2184.

20. Kloos RT, Eng C, Evans DB, Francis GL, Gagel RF, Gharib H, Moley JF, Pacini $F$, Ringel MD, Schlumberger M, et al. Medullary thyroid cancer: management guidelines of the American Thyroid Association. Thyroid. 2009; 19(6):565-612.

21. Miyauchi A, Onishi T, Morimoto S, Takai S, Matsuzuka F, Kuma K, Maeda M, Kumahara Y. Relation of doubling time of plasma calcitonin levels to prognosis and recurrence of medullary thyroid carcinoma. Ann Surg. 1984; 199(4):461-6.

\section{Publisher's Note}

Springer Nature remains neutral with regard to jurisdictional claims in published maps and institutional affiliations. 